\title{
UNUSUAL SPERMATOZOAN FORMATIONS IN THE EPIDIDYMIS OF THE FLYING SQUIRREL (GLAUCOMYS VOLANS)
}

\author{
JAN MAR'TAN AND ZDENEK HRUBAN \\ Department of Zoology, Southern Illinois University, Carbondale, \\ Illinois, and Department of Pathology, University of Chicago, Illinois
}

(Received 26th February 1969)

\begin{abstract}
Summary. In the upper caput epididymidis of Glaucomys volans, where epithelial cells have a high concentration of RNA in their apical cytoplasm, spermatozoa form long cylindrical bodies. Spermatozoan tails, adhering together, fill the interior of the cylinder. Their heads, with closely attached cytoplasmic droplets, are regularly arranged on the periphery of the cylinder with acrosomes facing the epididymal epithelium. In subsequent segments of the epididymis, the cylindrical bodies become more compact and the sperm heads are drawn together in rouleaux.

In the lower caput epididymidis, cylindrical bodies fragment and masses of individual spermatozoa or spermatozoa grouped in rouleaux fill the lumina of the duct. It is suggested that in the flying squirrel the maturation of spermatozoa is accompanied by changes in their cohesive properties.
\end{abstract}

Some mammalian spermatozoa show specific grouping during their journey through the epididymal duct. Biggers, Creed \& DeLameter (1963) observed conjugated spermatozoa in all investigated American marsupials. Rouleaux formation of spermatozoa in the guinea-pig was described by Fawcett \& Hollenberg (1963). The present report is concerned with unusually complex formations of spermatozoa and some characteristics of epididymal epithelium found in the flying squirrel.

Two adult male flying squirrels were killed at the beginning of March. At autopsy, both testes and epididymides were excised and fixed in $10 \%$ neutral formalin. Tissues were embedded in paraffin by standard methods, sectioned at $6 \mu$ and stained. Carbohydrates were demonstrated by the periodic acidSchiff reaction (PAS), and sections digested for $1 \mathrm{hr}$ at $37^{\circ} \mathrm{C}$ with malt diastase in $0.02 \mathrm{M}$-phosphate buffer at $\mathrm{pH} 6.0$ (Lillie, 1965) served as controls.

Ribose nucleic acid was localized by staining with Azure B at pH 4.0 (Swift, 1955). Control sections were incubated for $2 \mathrm{hr}$ at $50^{\circ} \mathrm{C}$ in $0.02 \%$ ribonuclease (Sigma) in distilled water adjusted to $\mathrm{pH} \mathrm{6.8} \mathrm{(Barka} \mathrm{\&} \mathrm{Anderson,} \mathrm{1963).}$ Protein was stained by the mercury bromphenol method (Barka \& Anderson, 1963) and mitochondria by Kull's aurantia method (Baker, 1956). 
Epithelial cells of the first two segments of the caput epididymidis have their cytoplasmic RNA concentrated in the perinuclear region, especially under the nucleus (Pl. 1, Figs. 1, 2). The tall columnar cells of the initial segment also have much cytoplasmic RNA scattered in their apical parts, and the shorter cells of the second segment have a compact RNA mass located just above the Golgi region (Pl. 1, Figs. 1, 2). Mitochondria are concentrated in the apical cytoplasm of the cells in the first two segments and this region also stains strongly positive for protein ( $\mathrm{Pl}$. 1, Fig. 3). The positive material appears as granules or vacuoles with weakly positive centres.

In other segments of the caput, cytoplasmic RNA is not as abundant as in the first two segments and the cells stain only moderately with mercury bromphenol blue. However, Wilder's reticulum technique shows a vacuolated apical cytoplasm in all segments of the caput epididymidis. All the above reactions for cytoplasmic RNA are abolished by pre-treatment with ribonuclease.

Apical parts of some cells in the lower caput, and the cytoplasm of the majority of cells in the upper corpus, give a positive cytochemical reaction for glycogen. This PAS reactivity is abolished by diastase digestion. Glycogen is also observed in the epithelial cells of the ductuli efferentes.

Spermatozoa which are scattered in the lumina of the seminiferous tubules, ductuli efferentes and in the initial segment of the epididymis form long cylindrical bodies in the second segment of the epididymis. The contours of these bodies closely follow the coils of the epididymal duct. The heads of individual spermatozoa with closely attached cytoplasmic droplets are regularly spaced on the periphery of these bodies with their acrosomes toward the epididymal epithelium (Pl. 1, Figs. 2, 3). The tails, forming obtuse angles with the sperm heads, fill the inside of the cylinders (Pl. 1, Figs. 2, 3). Sperm heads are often seen in profile both in cross sections and longitudinal sections of the cylindrical bodies as if the heads were slanted on their necks (Pl. 1, Figs. 2, 3). In the following segments of the caput epididymidis, the sperm heads rotate so that in cross sections of the cylindrical bodies they are always seen from the flat

\section{EXPLANATION OF PLATE 1}

All figures magnified $\times 640$.

Fig. 1. Initial segment of the epididymis. Arrows point to basal (white arrow) and apical (black arrow) locations of cytoplasmic RNA. PAS-Azure B.

Fig. 2. Segment two. Arrows point to basal (white arrow) and apical (black arrow) locations of cytoplasmic RNA. The lumen contains a cross section through the cylindrical body. PAS-Azure B.

Fig. 3. Longitudinal section through the cylindrical body in segment two. Arrow points to cytoplasmic droplets located under sperm heads. Notice strongly positive reaction in apical region of epithelial cells. Feulgen-bromphenol blue.

Fig. 4. Cross section through cylindrical body in the middle caput. Notice spermatozoa forming rouleaux in the cylindrical body and compare with Fig. 2. Haematoxylin-eosin. Fig. 5. Longitudinal section through cylindrical body in middle caput. Arrow points to rouleaux formations in the cylindrical body. Compare with Fig. 3. Kull's.

Fig. 6. Spermatozoa dispersed in lower caput. Arrow points to cytoplasmic droplet located at the distal end of the middle piece. Some spermatozoa are single, others in rouleaux. Bromphenol blue. 
PL.ITli;
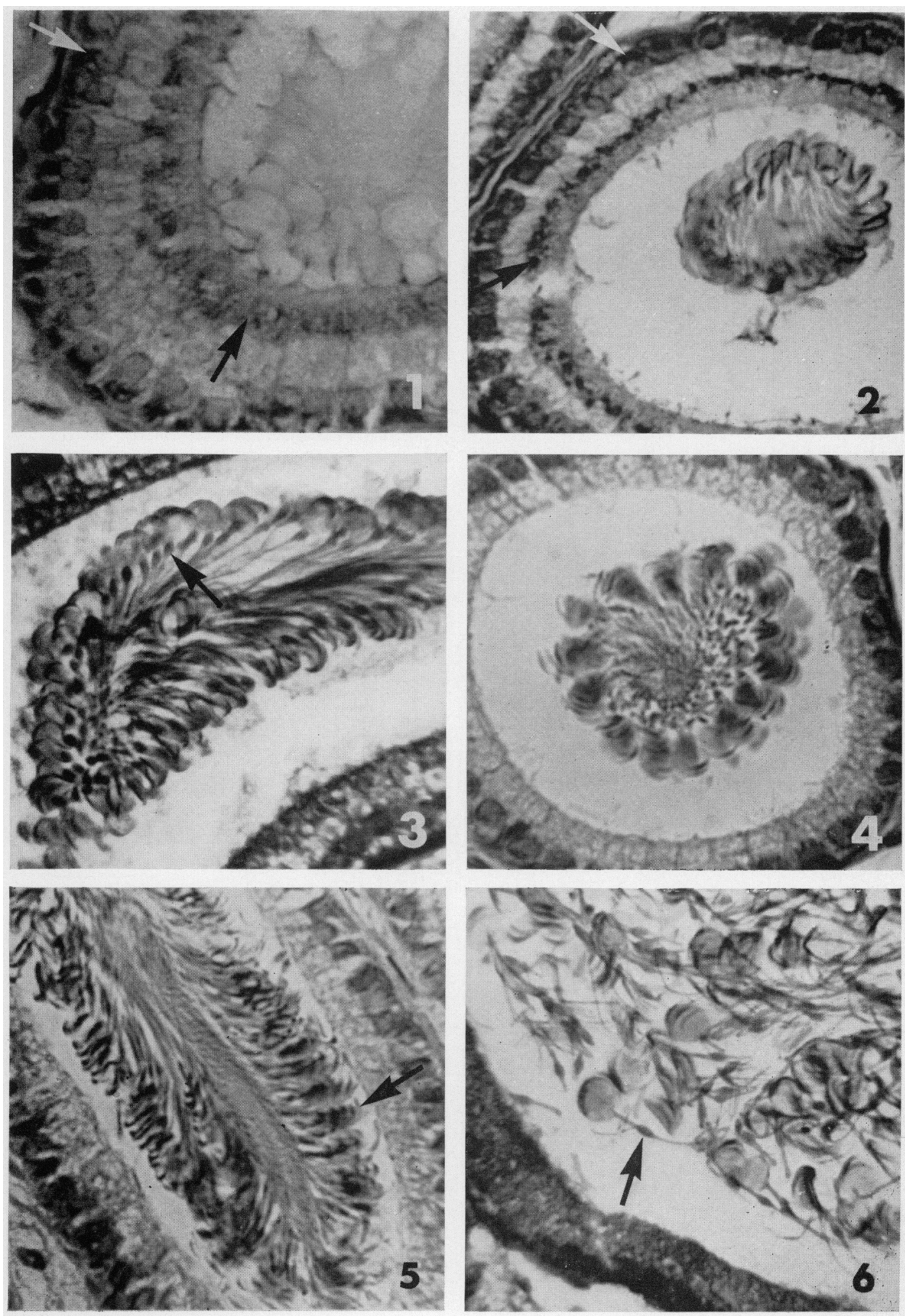
surface, while in longitudinal sections they are seen in profile (Pl. 1, Figs. 4, 5). At this time, spermatozoa become tightly packed in the cylindrical bodies and their heads, drawn together closely into groups, exhibit rouleaux formation (Pl. 1, Figs. 4, 5). Spermatozoa remain in this order during their journey through the remainder of the upper and middle caput epididymidis. The symmetry of the cylindrical bodies slowly diminishes as they come apart in the lower caput. By this time, cytoplasmic droplets have migrated to the distal end of the sperm middle piece (Pl. 1, Fig. 6).

In the corpus and cauda epididymidis, the lumina of the duct are filled with masses of disorganized spermatozoa, the majority of which still have their cytoplasmic droplets attached. Some spermatozoa are single; others, with acrosomes adhering to one another, form rouleaux (Pl. 1, Fig. 6).

During the early stages of the formation of the cylindrical bodies, individual spermatozoa cohere only by their tails, which fill the interior of the cylinder (Pl. 1, Fig. 3). Later, when the sperm heads are drawn together, spermatozoa seem to adhere to one another along their entire length (Pl. 1, Fig. 5). Still later, when the cylindrical bodies break up, the sperm heads alone cohere, forming rouleaux (Pl. 1, Fig. 6).

According to current theory, spermatozoa in the mammalian epididymis are motionless and are carried passively down the duct by contractions of the epididymis (Risley, 1963). The regular arrangement described for the epididymal spermatozoa in the flying squirrel, however, seems to require some active movement on the part of the individual spermatozoa. The glycogen which was observed in the epithelial cells of the ductuli efferentes and of the epididymis may be the source of energy needed for such manœuvres.

The formation of cylindrical bodies in the flying squirrel may be an intrinsic feature of the spermatozoa, or a result of the action on spermatozoa by the epithelial cells of the caput epididymidis. The apposition of sperm heads to the epididymal epithelium supports the second possibility (Pl. 1, Figs. 2, 3, 4, 5) and the presence of ribose nucleic acid in the apical epithelium of the first two segments, where the cylindrical formations first appear, also suggests that the spermatozoa may be influenced by the secretory activity of the epithelial cells in this region (Pl. 1, Figs. 1, 2).

The unusual amount of cytoplasmic RNA and the strong apical reaction with mercury bromphenol technique point to some protein as a secretory product.

Migration of the cytoplasmic droplet of an individual spermatozoon begins at the time of formation of the cylindrical bodies and ends with the fragmentation of these bodies. Movement of the cytoplasmic droplet to the distal end of the middle piece is interpreted as a sign of sperm maturation; it is possible that cylindrical body formation is necessary for this maturation.

The cohesive forces which keep spermatozoa in the cylindrical formation appear first in the sperm tail and later spread over the entire spermatozoon. These cohesive properties are probably located in the sperm cell membrane and their nature is not known. When cylindrical bodies disintegrate, the cohesiveness remains only in the heads of those spermatozoa which form rouleaux. These observations indicate that maturation of spermatozoa in the 
flying squirrel is accompanied by changes in their cell membranes with consequent diminution of cohesive properties either in strength or in area.

To date, rouleaux formation of spermatozoa has only been reported in the guinea-pig (Fawcett \& Hollenberg, 1963). These authors found an increase in the cohesiveness of the more mature spermatozoa.

The males in the present study were killed in early March when, according to Asdell (1964), a mating season of this seasonal breeder begins. A study of their testes confirmed the breeding condition of these animals. A comparative study of the epididymides of the Glaucomys volans out of the mating season may shed some light on the unsolved problems mentioned in this work.

Supported in part by Grant No. GA-05310 from National Cancer Institute, National Institute of Health, Public Health Service.

\section{REFERENCES}

Asdell, S. A. (1964) Pattems of mammalian reproduction. Cornell University Press, Ithaca, New York.

BAKER, J. R. (1956) Cytological technique, 3rd impression. Methuen, London.

Barka, T. \& ANderson, P.J. (1963) Histochemistry. Harper \& Row, New York.

Biggers, J. D., Creed, R. F. S. \& Delameter, E. D. (1963) Conjugated spermatozoa in American marsupials. 7. Reprod. Fert. 6, 324.

Fawcert, D. W. \& Holl.enberg, R. D. (1963) Changes in the acrosome of guinea pig spermatozoa during passage through the epididymis. Z. Zellforsch. mikrosk. Anat. 60, 276.

LILLIE, R. D. (1965) Histopathologic technic and practical histochemistry, 3rd edn. Blakiston, New York.

Risley, P. L. (1963) Physiology of the male accessory organs. In: Mechanisms concerned with Conception. Ed. C. G. Hartman. Pergamon Press, New York.

SwrFt, H. (1955) Cytochemical techniques for nucleic acids. In: The Nucleic Acids, Vol. 2, pp. 51-92. Eds. E. Chargaff and J. N. Davidson. Academic Press, New York. 